\title{
As partes e o todo: possíveis efeitos dos sistemas de memórias de tradução na produção do tradutor em formação
}

\section{The parts and the whole: possible effects of translation memory systems in translations of trainee translators}

\author{
Érika Nogueira de Andrade Stupiello* \\ Lara Cristina dos Santos Talhaferro**
}

Resumo: Os sistemas de memórias de tradução são hoje um componente essencial de apoio ao tradutor que presta serviços de tradução especializada e lida com volumosos materiais textuais. Tendo por função básica fragmentar e armazenar a produção tradutória para posterior recuperação em trabalhos afins, essas ferramentas oferecem ao tradutor uma visão compartimentada do texto. Buscando investigar os possíveis efeitos da adoção de sistemas de memórias na produção de tradutores em formação, este trabalho apresenta resultados de uma pesquisa que comparou traduções de dois textos comerciais com e sem o auxílio de um sistema de memória. Os resultados indicam que a segmentação pode influenciar tanto a produção quanto a organização do texto traduzido.

Palavras-chave: Sistemas de memórias de tradução; segmentação textual; Wordfast.

Abstract: Translation memory systems are at present an essential component to support the work of the translator providing specialized translation services and dealing with large volumes of texts. These tools, which segment and store translations for future reuse in similar works, offer the translator a segmented view of the text.

\footnotetext{
* Professora do curso de Bacharelado em Letras com Habilitação de Tradutor da Unesp de São José do Rio Preto, São Paulo. E-mail: erika@ibilce.unesp.br.

** Bacharela do curso Letras com Habilitação de Tradutor da Unesp de São José do Rio Preto, São Paulo. E-mail: lara.talhaferro@hotmail.com.
} 
Stupiello, E. N. De A.; Talhaferro, L. C. dos S. - As partes e o todo: possíveis efeitos dos sistemas de memórias de tradução na produção do tradutor em formação

Seeking to investigate the possible effects of the adoption of translation memories in the production of trainee translators, this paper presents the results of a study comparing the translation of two commercial texts carried out with and without the assistance of a translation memory system. The results suggest that segmentation may influence both the production and organization of the translated text.

Keywords: Translation memory systems; text segmentation; Wordfast.

\section{Introdução}

Uma das ferramentas de auxílio à tradução que mais ganhou popularidade entre tradutores nas últimas décadas foram os sistemas de memórias de tradução (AUSTERMÜHL 2001; BOWKER 2002; SOMERS 2003). Constituídos basicamente por um arquivo bilíngue de segmentos de textos originais e suas respectivas traduções e com a capacidade de identificar e recuperar esses fragmentos de traduções em trabalhos posteriores, esses sistemas têm por principal atributo proporcionar um aumento de produtividade ao tradutor ao permitir-lhe reutilizar trechos já traduzidos de maneira rápida e eficiente. Idealmente, em trabalhos com um alto índice de repetição, ou em versões atualizadas de um mesmo material, o tradutor teria condições de traduzir mais em menos tempo.

Chamando a atenção para o "relacionamento privilegiado" que o tradutor sempre cultivou com suas ferramentas de trabalho (desde simples listas de palavras a dicionários monolíngues e bilíngues) em diferentes épocas, Cronin (2003: 24) realça a importância desses objetos para a prática tradutória, declarando que "a tradução sem ferramentas simplesmente não existe". Todavia, especialmente nos dias de hoje, em que as ferramentas associam-se a tecnologias, a preocupação do tradutor parece voltar-se exclusivamente ao domínio de seus recursos visando à aplicação imediata e ao retorno financeiro do investimento que tais sistemas exigem. Nessas condições de trabalho regidas 
Stupiello, E. N. De A.; TAlhaferro, L. C. Dos S. - As partes e o todo: possíveis efeitos dos sistemas de memórias de tradução na produção do tradutor em formação

por prazos escassos, não há espaço para se refletir sobre os possíveis efeitos na atividade tradutória da adoção de sistemas de memórias ou, ainda segundo Cronin, sobre as “implicações mais amplas de sua presença no mundo da tradução (o que elas representam)" (2003: 28). ${ }^{1}$

No ambiente de ensino de tradução, o funcionamento de uma ferramenta é, quase sempre, apresentado exclusivamente em sessões de treinamento, que não reserva tempo para a análise do processamento do texto pelo sistema ou da tradução produzida com auxílio de seus recursos. Ao investigar um sistema de memória em uso e apresentar dados de uma análise de traduções realizadas com e sem esse auxílio, este trabalho busca contribuir para o entendimento dos benefícios e das limitações do uso dessa ferramenta pelo tradutor em formação.

Conforme atesta Bowker (2005: 19), em um estudo piloto sobre o impacto de sistemas de memórias na qualidade do trabalho de tradução, não é incomum ao tradutor novato ou em treinamento ser induzido pela empolgação de poder acelerar seu trabalho, o que pode resultar no desenvolvimento de uma confiança excessiva - ou uma "fé cega", nas palavras da autora -, na capacidade do sistema. A convicção de que o controle da ferramenta é exercido pelo seu usuário pode acabar colaborando para que o tradutor não questione um segmento que lhe foi apresentado como totalmente correspondente ao novo trecho em tradução ou para que ele reflita sobre a possível influência de uma visualização segmentada do texto na sua leitura e interpretação e, ainda, na construção da coesão e coerência do texto traduzido.

Os mesmos recursos que conferem produtividade ao tradutor, poupandolhe de retraduzir trechos já traduzidos e auxiliando-o na padronização terminológica também podem interferir na interpretação que ele constrói do texto de origem. Essa situação pode ocorrer já no momento em que o sistema apresenta o texto a ser traduzido ao tradutor, que o visualiza em segmentos delimitados por sinais de pontuação e outras marcas de quebra de texto.

Este trabalho centra-se na análise do recurso de segmentação, que

\footnotetext{
${ }^{1}$ Esta e as demais citações em língua estrangeira foram traduzidas pelas autoras.
} 
Stupiello, E. N. De A.; TAlhaferro, L. C. Dos S. - As partes e o todo: possíveis efeitos dos sistemas de memórias de tradução na produção do tradutor em formação

constitui a base da funcionalidade desses sistemas, e apresenta dados de um estudo da produção de tradutores em formação assistidos ou não por sistemas de memórias. 0 objetivo da pesquisa foi avaliar os possíveis efeitos da aplicação dessa ferramenta na produção da tradução de dois textos comerciais, considerados bons candidatos ao emprego de sistemas de memórias.

0 trabalho é organizado em quatro partes. A segunda seção, que segue esta introdução, trata de como os sistemas de memórias são concebidos e das possíveis implicações do uso de seus recursos pelo mercado de trabalho que os utiliza e que acolherá os tradutores em formação. A terceira seção apresenta resultados de uma pesquisa realizada com alunos do terceiro ano de um curso de graduação em tradução sobre os efeitos da aplicação de sistemas de memórias na tradução de textos comerciais. A quarta apresenta as considerações finais e propõe possíveis direcionamentos para a pesquisa.

\section{Os sistemas de memória na teoria: aplicações e implicações}

Para que possa ser processado por um sistema de memória, todo texto é dividido em segmentos, cada um destes considerado a "menor unidade traduzível" pela ferramenta (EsSELINK 2000). A função primordial da segmentação seria a de gerar correspondências (matches) bilíngues que, armazenadas na memória, teriam maiores chances de ocorrerem em outros textos e, nesses casos, serem retomadas e aproveitadas em outros trabalhos.

Um segmento armazenado é recuperado quando o sistema identifica uma correspondência em seu banco de dados segundo uma porcentagem de semelhança definida. 0 grau de correspondência entre o segmento de origem e um segmento traduzido definirá a recuperação e reapresentação ao usuário, ou não, pelo sistema. As correspondências podem ser exatas (exact) ou parciais 
Stupiello, E. N. De A.; TAlhaferro, L. C. Dos S. - As partes e o todo: possíveis efeitos dos sistemas de memórias de tradução na produção do tradutor em formação

(fuzzy), conforme um determinado índice definido pelo usuário.

Sobre as correspondências exatas, Bowker (2002: 97) lembra que, "mesmo quando o sistema de memória de tradução recupera o que aparenta ser uma correspondência exata, o tradutor não é obrigado a aceitar a tradução proposta". Sendo um segmento recuperado parte de um novo texto, seria ideal que o tradutor analisasse se a correspondência está adequada ao contexto da tradução, se há erros na memória que possam ter passado despercebidos em traduções anteriores ou se a tradução pode ser melhorada de alguma forma. Porém, a realidade de trabalho do tradutor é bastante diferente, conforme constata Weininger:

0 tradutor, orientado para não alterar 100\%-matches e não recebendo remuneração por este trabalho importante de revisão/eliminação de erros e inconsistências, ainda por cima com prazos exíguos e tarifas cada vez menores, simplesmente fecha os olhos e tenta empurrar o problema de volta para a origem. (WEININGER 2004: 256)

Segundo o autor, para atender às necessidades mercadológicas, os tradutores ignoram a qualidade do texto produzido por conta do prazo a ser cumprido, principalmente porque não há incentivos econômicos que estimulem o profissional a realizar um trabalho que vá além do que the foi incumbido. Nesse sentido, os sistemas de memórias de tradução, em vez de auxiliarem os tradutores, podem comprometer a qualidade de seu trabalho.

Se correspondências consideradas exatas dispensariam a atenção e a revisão do tradutor, não se pode dizer o mesmo de correspondências ditas parciais. Uma correspondência parcial ocorre quando a memória recupera um segmento semelhante, mas não igual a um novo segmento. Considerando a diferença entre correspondências exatas e parciais, pode-se presumir que, ao lidar com grandes extensões de texto, a tendência do tradutor pode ser de concentrar-se nos segmentos não traduzidos e nas correspondências parciais, deixando por último (e, até, ignorando, por não ser remunerado), as 
Stupiello, E. N. DE A.; TAlHAferro, L. C. dOS S. - As partes e o todo: possíveis efeitos dos sistemas de memórias de tradução na produção do tradutor em formação

correspondências exatas.

Essa situação parece se tornar ainda mais evidente em trabalhos contratados por agências de tradução. Como aponta um estudo conduzido por LeBlanc (2013) em agências de tradução do Canadá, boa parte do descontentamento dos tradutores contratados relaciona-se com a maneira como as ferramentas são empregadas, não como um instrumento para o aumento da qualidade, mas como um recurso para aumento de produtividade. Conforme explica, “a ideia é construir novas memórias de tradução e alimentar com dados novos as memórias existentes, preenchendo-as, assim multiplicando as possibilidades para reutilização" (LEBLANC 2013: 5).

O primeiro motivo que justifica tal exigência seria o tempo. Uma das maiores qualidades divulgadas para um sistema de memórias de tradução é a economia do tempo que ele pode promover no trabalho do tradutor. LeBlanc (2013) afirma que, quando se trata das vantagens do uso de sistemas de memórias de tradução, o ganho de produtividade é o primeiro fator a ser lembrado pelos tradutores. Por outro lado, a possível economia em tempo proporcionada pelos sistemas é oferecida à custa da fragmentação do texto de origem, uma consequência que, segundo o pesquisador, afetaria diretamente a relação do tradutor com o texto:

a principal desvantagem dos sistemas de memória de tradução é que eles forçam os tradutores a utilizar uma abordagem de frase por frase, pela qual eles são forçados a trabalhar com segmentos (unidades de tradução) no lugar de o texto completo. Ao trabalhar dessa maneira, a reorganização do texto de chegada (combinação, divisão, movimentação nas frases) torna-se mais complicada (se não impossível) e consome mais tempo do que antes. (LEBLANC 2013: 7)

Um dos efeitos mais diretos do modo como os sistemas de memórias apresentam o texto original ao tradutor pode estar na composição do texto final traduzido, em especial quando a memória é empregada por tradutores novatos, cuja falta de experiência pode levá-los a depender demais da configuração dos segmentos pela memória e das sugestões por ela apresentadas. Essa 
Stupiello, E. N. DE A.; TAlhaferro, L. C. dos S. - As partes e o todo: possíveis efeitos dos sistemas de memórias de tradução na produção do tradutor em formação

constatação, apontada pelo estudo citado de Bowker (2005), é corroborada pelos tradutores recém-contratados entrevistados por LeBlanc que admitem que "confiam demasiadamente nos sistemas de memórias" e que, por serem desencorajados a olhar além dos segmentos do texto de origem apresentados para tradução, acabam "relutando em aventurar-se sozinhos e oferecer soluções novas e inovadoras" (LEBLANC 2013: 8).

Percebe-se, com essa declaração reportada por LeBlanc, que a pretendida "economia de tempo" com a adoção dos sistemas de memória prevalece sobre qualquer tentativa ou empenho em buscar soluções diferentes para a tradução de um texto. Por outro lado, constata-se que a referida economia de tempo não é necessariamente imediata. Bowker (2002) explica que, toda vez que um profissional adota uma nova ferramenta de trabalho, há uma curva de aprendizado. Além disso, considerando o fato de que é a produção do tradutor que alimenta o banco de dados da memória, ganhos na produtividade costumam aparecer de médio a longo prazo, pois somente quando há uma quantidade considerável de unidades de tradução na memória existe maior chance de o sistema reutilizá-las com maior frequência.

A qualidade é outro fator relacionado ao uso de sistemas de memórias de tradução. Por um lado, esses sistemas ajudam o tradutor a manter a consistência e a padronização de textos repetitivos, além de serem ferramentas úteis na tradução de um texto de grande volume por uma equipe de tradutores. Por outro, a qualidade das unidades de tradução depende da competência do usuário. Weininger (2004) e LeBlanc (2013) relatam casos de tradutores inexperientes que, em contato com memórias de tradução já existentes, não conseguiam julgar se seu trabalho estava adequado ou não. Tradutores experientes também podem ser afetados negativamente pelo uso de memórias de tradução, quando não revisam os segmentos considerados de correspondência total, a fim de reduzir o tempo de realização do trabalho.

A qualidade dos textos também diminui em razão da segmentação realizada pelo sistema. Se um tradutor traduz um texto segmento a segmento e, na revisão, mantém a segmentação inalterada, sem utilizar elementos de 
Stupiello, E. N. De A.; TAlhaferro, L. C. dos S. - As partes e o todo: possíveis efeitos dos sistemas de memórias de tradução na produção do tradutor em formação

coesão e coerência para possivelmente aproveitar com mais facilidade esse segmento, ele pode comprometer a fluidez e a naturalidade desse texto. A revisão é uma questão também ligada à memória de tradução. As memórias precisam passar constantemente por um controle de qualidade, a fim de reduzir erros e atualizar terminologia.

Para que a produtividade auxiliada pelo uso de sistemas de memórias de tradução seja maior, Weininger (2004: 253) afirma que pesquisadores estariam estudando fatores relacionados à complexidade da linguagem, tais como "tamanho médio de palavra / frase, quantidade de vírgulas por frase, frequência de verbos modais e auxiliares, presença de terminologia préexistente no dicionário do sistema de TM" a fim de produzir programas de computador para identificar e reduzir esses elementos, visando ao maior aproveitamento do recurso da memória. A partir da observação do autor, podemos pensar que é possível que traduções tenham propósitos diferentes e que, para cada propósito, existe um parâmetro de qualidade. Um documento, o qual necessite apenas de um conhecimento imediato, elementar e superficial, pode ser beneficiado pelo suprimento de elementos que o tornem complexo, sofrendo o ônus da menor naturalidade. No entanto, para um documento que tenha grande repercussão pública e que precise de um nível de entendimento aprofundado, um trabalho executado em sua maioria por inteligência artificial não é o bastante.

Outra questão relacionada aos sistemas de memórias de tradução aqui tratada é a da responsabilidade sobre os textos. No contexto de grandes empresas, agências de tradução e órgãos internacionais, em que grandes volumes textuais são produzidos, traduzidos e editados e onde geralmente as memórias de tradução são compartilhadas e, sempre quando possível, reaproveitadas por diferentes pessoas, a concepção de texto se perde, dado o fato de o material linguístico estar constantemente passando por edições.

Tendo discutido o modo como os sistemas de memórias de tradução são concebidos e empregados no mercado de trabalho, apresentamos a seguir o uso dessas ferramentas na prática de tradutores em formação, buscando refletir 
Stupiello, E. N. De A.; TAlhaferro, L. C. dos S. - As partes e o todo: possíveis efeitos dos sistemas de memórias de tradução na produção do tradutor em formação

sobre as possíveis implicações da leitura segmentada de um texto.

\section{Os sistemas de memórias de tradução na prática: análises estatística e contrastiva de traduções de textos comerciais}

Considerando que a prática corrente do mercado de trabalho que emprega sistemas de memórias de tradução trata o texto como um conjunto de segmentos passíveis de recuperação e edição em novos contextos,

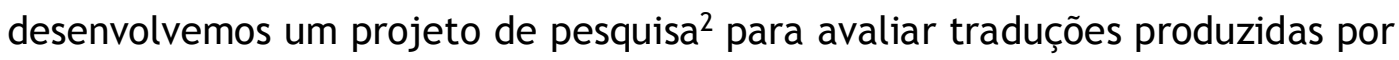
estudantes em formação assistidos ou não pelo sistema de memória Wordfast Classic. Foram avaliadas doze traduções para o português de dois textos em inglês: um acordo de confidencialidade e um termo com normas para aluguel de carros.

As traduções dos dois documentos originais foram realizadas por seis alunos, três deles utilizando o Wordfast (Aluno 1, Aluno 2, Aluno 3) tanto no acordo de confidencialidade quanto no termo de normas para aluguel de carros, e três que não utilizaram esse sistema em nenhum dos dois textos (Aluno 4, Aluno 5, Aluno 6). Os trabalhos foram submetidos a uma análise estatística, focada no percentual de semelhança entre os textos, e a um exame contrastivo, constituído pelo cotejamento entre trechos dos originais e suas respectivas traduções.

Para a análise quantitativa dos dados, foi utilizado o software Turnitin, uma ferramenta de verificação da originalidade de trabalhos e de prevenção de plágios. Esse programa permite a comparação de textos em seu depositório, ou

2 Esta pesquisa foi financiada pela Fapesp (Processo n. 2013/15841-0) e cadastrada na Plataforma Brasil. Cada participante assinou um Termo de Consentimento Livre e Esclarecido (TCLE) garantindo o anonimato na divulgação dos resultados.

TradTerm, São Paulo, v. 25, Agosto/2015, pp. 13-37

www.usp.br/tradterm

http://www.revistas.usp.br/tradterm/index 
Stupiello, E. N. De A.; TAlhaferro, L. C. dos S. - As partes e o todo: possíveis efeitos dos sistemas de memórias de tradução na produção do tradutor em formação

seja, o cotejamento limitado aos textos submetidos. Ele processa os textos enviados, destacando as semelhanças detectadas e apresentando a porcentagem de similaridade entre os textos e os bancos de dados. A função do Turnitin utilizada foi o OriginalityCheck, que compara um documento submetido aos outros documentos armazenados em sua base de dados e a outros documentos anexados. Por meio do OriginalityCheck foi possível identificar precisamente o grau de semelhança entre as seis traduções de cada texto analisado, tanto entre os textos traduzidos com o Wordfast, os traduzidos sem o programa e as seis traduções de cada documento traduzido.

Com o auxílio do Turnitin, foi possível observar que os textos, de maneira geral, têm alto grau de similaridade. Esse alto nível de semelhança pode ser explicado pela natureza dos textos analisados, visto que os originais cerram ajustes formais relacionados a negociações e que, portanto, são geralmente redigidos de modo que sejam fácil e claramente entendidos pelas partes envolvidas no negócio, sem o emprego excessivo de conotações ou ambiguidades.

Constatamos que o uso do Wordfast não teve grande influência no grau de similaridade entre os textos traduzidos. A figura a seguir mostra o relatório geral do Turnitin sobre o grau de similaridade entre os dois documentos analisados no trabalho, com e sem o auxílio do Wordfast. Cada cor representa um bloco de três traduções, que varia conforme o documento traduzido e a utilização ou não do sistema de memórias de tradução. A cor rosa indica o acordo de confidencialidade com o uso do Wordfast; a cor azul, o mesmo acordo e a não utilização do sistema. A cor lilás, por sua vez, designa o termo com normas para aluguel de carros traduzido com o sistema Wordfast e a cor verde especifica o termo sem a utilização da memória. 
Stupiello, E. N. De A.; TAlhaferro, L. C. Dos S. - As partes e o todo: possíveis efeitos dos sistemas de memórias de tradução na produção do tradutor em formação
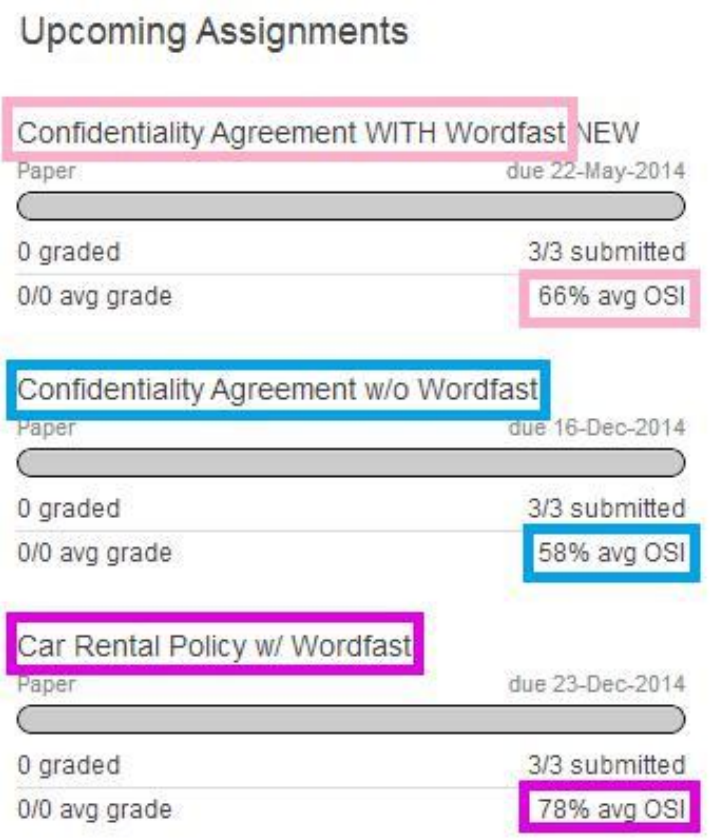

\begin{tabular}{l|l}
\hline $\begin{array}{l}\text { Car Rental Policy w/o Wordfast } \\
\text { Paper }\end{array}$ & due 23-Dec-2014 \\
\hline $0 / 0$ avg grade & $3 / 3$ submitted \\
\hline
\end{tabular}

Figura 1: Relatório geral do Turnitin sobre o grau de similaridade entre as traduções dos dois documentos analisados, com e sem o Wordfast.

O grau de similaridade, tanto no acordo de confidencialidade quanto no termo de normas para aluguel de carros, foi maior com o uso do Wordfast. No acordo, os textos traduzidos com a utilização do programa tiveram uma semelhança de 66\%, ao passo que as traduções realizadas sem o Wordfast apresentaram similaridade de 58\%. No termo, as traduções feitas com 0 Wordfast foram semelhantes em 78\%, à medida que os textos traduzidos sem 0 uso do programa foram similares em 65\%. Apesar de esses índices não representarem diferenças significativas, eles indicam que os participantes que 
Stupiello, E. N. De A.; TAlhaferro, L. C. dos S. - As partes e o todo: possíveis efeitos dos sistemas de memórias de tradução na produção do tradutor em formação

utilizaram o sistema de memória na tradução desenvolveram trabalhos mais próximos ao texto de origem. Esses resultados podem ser explicados pela segmentação textual do texto de origem, que volta a atenção do tradutor para uma parte do texto e não para o todo.

Em seguida à análise estatística, procedemos a comparação entre trechos dos originais e suas respectivas traduções. Foram avaliados critérios relacionados à segmentação do texto pelo sistema de memórias de tradução, como coesão, coerência e estrutura textual.

Apresentamos neste trabalho dois trechos do acordo de confidencialidade e um trecho do termo de condições para aluguel de veículos para análise. Essa seleção foi realizada a partir de um cotejamento prévio e dos trechos marcados como idênticos pelo recurso OriginalityCheck.

\subsection{Acordo de confidencialidade}

$\mathrm{O}$ acordo de confidencialidade analisado neste trabalho foi um contrato celebrado entre duas empresas. 0 documento trata das disposições necessárias para a troca de informações consideradas confidenciais, estabelecendo que essas informações sejam utilizadas para a realização de um propósito comum.

0 primeiro trecho a ser analisado neste trabalho é a frase que afirma que as partes do contrato estão de acordo com o conteúdo do documento. Esse fragmento é visto depois do preâmbulo, texto que introduz o contrato, apresentando as partes envolvidas e os motivos pelos quais o contrato é celebrado.

Trecho original 1: “THEREFORE, THE PARTIES ARE IN AGREEMENT with the following:"

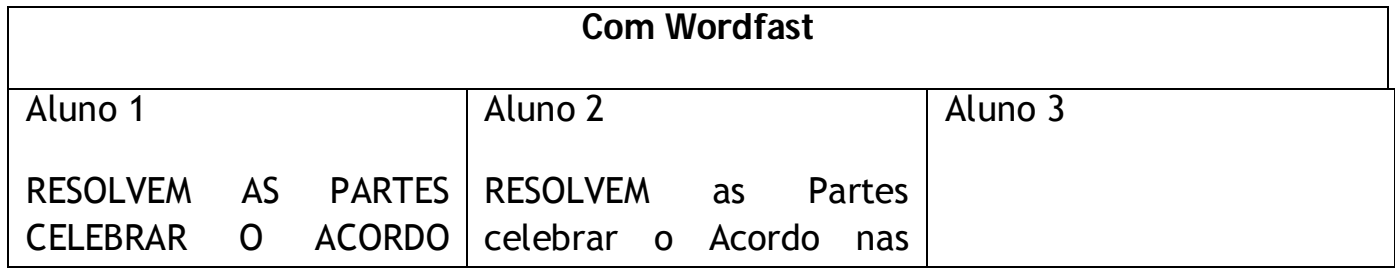


Stupiello, E. N. DE A.; TAlHaferro, L. C. dos S. - As partes e o todo: possíveis efeitos dos sistemas de memórias de tradução na produção do tradutor em formação

\begin{tabular}{|l|l|l|}
\hline $\begin{array}{l}\text { segundo as cláusulas a } \\
\text { seguir: }\end{array}$ & $\begin{array}{l}\text { cláusulas e condições a } \\
\text { seguir: }\end{array}$ & $\begin{array}{l}\text { POR MEIO DESTE } \\
\text { INSTRUMENTO as partes } \\
\text { concordam: }\end{array}$ \\
\hline \multicolumn{1}{|c|}{ Sem Wordfast } \\
\hline $\begin{array}{l}\text { Aluno 4 sendo, fica } \\
\text { acordado entre as partes, } \\
\text { como segue: }\end{array}$ & $\begin{array}{l}\text { Aluno 5 } \\
\text { ASSIM SENDO, POR MEIO } \\
\text { DESTE, CONCORDAM as artes como segue: }\end{array}$ & $\begin{array}{l}\text { Aluno 6 } \\
\text { Assim sendo, as Partes } \\
\text { concordam com o que } \\
\text { segue: }\end{array}$ \\
\hline
\end{tabular}

Neste trecho, uma tradução literal do texto original seria "Portanto, as partes estão de acordo com o que segue". É possível observar que os participantes que utilizaram o sistema de memória mantiveram a formatação do texto traduzido mais próxima àquela do texto de origem, mantendo a caixa alta no início da frase.

Nenhum dos estudantes que utilizou o software adicionou a seu texto uma palavra correspondente a "therefore". Não obstante, os alunos que não fizeram uso da ferramenta escolheram "assim sendo", expressão comum nos textos jurídico-comerciais para apresentar ao leitor uma conclusão que se mostra depois de serem postas determinadas colocações do acordo. Os alunos 1 e 2 optaram por "resolvem as partes celebrar o acordo" como correspondentes a "the parties are in agreement" e adicionaram a suas traduções, respectivamente, “as cláusulas” e “as cláusulas e condições”. 0 aluno 3 optou por explicitar o trecho "the following", que se refere ao acordo, traduzindo o trecho por “por meio deste instrumento", estrutura fixa nos textos jurídicos-comerciais que se refere ao documento em questão. 0 mesmo aluno fez uma inversão da ordem do texto original, posicionando "por meio deste instrumento" no início do período.

O Aluno 4 modificou a voz ativa que consta no original, utilizando a voz passiva analítica "fica acordado entre as partes". 0 Aluno 5 adicionou à sua tradução a estrutura "por meio deste", também comum em documentos jurídico-comerciais, que designa o próprio documento em questão. 0 Aluno 6 
Stupiello, E. N. De A.; Talhaferro, L. C. dos S. - As partes e o todo: possíveis efeitos dos sistemas de memórias de tradução na produção do tradutor em formação

foi quem, nesse trecho, mais se ateve ao original, não distanciando, porém, sua tradução do que é considerado apropriado para textos do mesmo gênero que sua tradução.

O trecho a seguir trata dos casos em que não é necessário haver confidencialidade:

\section{Trecho original 2: “7. EXEPTION AND COMPELLED DISCLOSURE}

7.1 The obligations of confidentiality in this Agreement does not apply to information:

(a) that are or become public domain in any way other than violation of this Agreement;

(b) that the Receiving Party can prove to have learned or acquired from third parties, provided that the third party is not subject to an obligation of confidentiality owed to the Discl osing Group regarding said information;

(c) that the Receiving Party can prove to have been released before the Disclosing Group and its representatives, or that has been independently developed by the Receiving Party without violating any of its obligations under this Agreement;

(d) which has its disclosure previousl y permitted in writing by the Disclosing Party; or

(e) which divulgation be required by law or by any authority that has jurisdiction over the Receiving Party."

\begin{tabular}{|l|l|l|}
\hline \multicolumn{2}{|c|}{ Com Wordfast } \\
$\begin{array}{l}\text { EXCEÇÃO E DIVULGAÇÃO } \\
\text { FORÇADA }\end{array}$ & $\begin{array}{l}\text { Aluno 2 } \\
\text { EXCEÇÃO E DIVULGAÇÃO } \\
\text { COMPULSÓRIA }\end{array}$ & $\begin{array}{l}\text { EXCEÇÃO E DIVULGAÇÃO } \\
\text { FORÇADA }\end{array}$ \\
$\begin{array}{l}\text { As obrigações de } \\
\text { confidencialidade } \\
\text { contidas neste Acordo não } \\
\text { se aplicam à informação: }\end{array}$ & $\begin{array}{l}\text { (a) que estiver ou entrar } \\
\text { em domínio público por } \\
\text { razões outras que a } \\
\text { violação deste Acordo; }\end{array}$ & $\begin{array}{l}\text { (a) que fazem parte do } \\
\text { domínio público por } \\
\text { motivo de violação do } \\
\text { presente Acordo; }\end{array}$ \\
$\begin{array}{l}\text { (a) que está em ou vem a } \\
\text { domínio público, exceto } \\
\text { se por violação deste } \\
\text { Acordo; }\end{array}$ & $\begin{array}{l}\text { (b) a qual a Parte } \\
\text { Receptora possa } \\
\text { demonstrar haver } \\
\text { recebido ou adquirido de }\end{array}$ & $\begin{array}{l}\text { (b) que o Receptor possa } \\
\text { demonstrar que recebeu } \\
\text { ou adquiriu de terceiros, } \\
\text { desde que o terceiro não }\end{array}$ \\
\hline
\end{tabular}

TradTerm, São Paulo, v. 25, Agosto/2015, pp. 13-37

www.usp.br/tradterm

http://www.revistas.usp.br/tradterm/index 
Stupiello, E. N. DE A.; TAlHaferro, L. C. dos S. - As partes e o todo: possíveis efeitos dos sistemas de memórias de tradução na produção do tradutor em formação

\begin{tabular}{|c|c|c|}
\hline $\begin{array}{l}\text { (b) que o Receptor } \\
\text { demonstrou ter recebido } \\
\text { ou adquirido de terceiros, } \\
\text { sendo que estes não } \\
\text { foram vinculados ou } \\
\text { sujeitos a uma obrigação } \\
\text { de confidencialidade em } \\
\text { relação ao Revelador, a } \\
\text { esse respeito; } \\
\text { (c) que o Receptor } \\
\text { demonstrou estar } \\
\text { disponível antes de ter } \\
\text { sido fornecida pelo } \\
\text { Revelador ou por seus } \\
\text { representantes, ou que } \\
\text { foi desenvolvida } \\
\text { independentemente pelo } \\
\text { Receptor sem a violação } \\
\text { de quaisquer das } \\
\text { obrigações dispostas } \\
\text { neste Acordo; } \\
\text { (d) que possa ser } \\
\text { divulgada, mediante } \\
\text { acordo prévio por escrito } \\
\text { com o Revelador; ou } \\
\text { (e) que deva ser } \\
\text { divulgada por exigência } \\
\text { da lei ou de qualquer } \\
\text { autoridade regulamentar } \\
\text { a cujo foro o Receptor } \\
\text { está sujeito. }\end{array}$ & $\begin{array}{l}\text { um terceiro, desde que } \\
\text { esse terceiro não esteja } \\
\text { obrigado ou sujeito a um } \\
\text { compromisso de } \\
\text { confidencialidade a esse } \\
\text { respeito pelo Grupo da } \\
\text { Parte Reveladora; } \\
\text { (c) a qual a Parte } \\
\text { Receptora possa } \\
\text { demonstrar haver sido } \\
\text { acessível antes de ser } \\
\text { fornecida pela Parte } \\
\text { Reveladora ou por seus } \\
\text { representantes, ou que } \\
\text { houver sido desenvolvida } \\
\text { de modo independente } \\
\text { pela Parte Receptora sem } \\
\text { violar nenhuma de suas } \\
\text { obrigações neste Acordo; } \\
\text { (d) cuja divulgação } \\
\text { houver sido previamente } \\
\text { acordada por escrito pela } \\
\text { Parte Reveladora; ou } \\
\text { (e) a qual tenha de ser } \\
\text { revelada por lei ou por } \\
\text { qualquer autoridade } \\
\text { reguladora aplicável a } \\
\text { cuja jurisdição a Parte } \\
\text { Receptora estiver sujeita. }\end{array}$ & $\begin{array}{l}\text { estiver vinculado nem } \\
\text { sujeito a uma obrigação } \\
\text { de confidencialidade } \\
\text { devida ao grupo o } \\
\text { Fornecedor em questão; } \\
\text { (c) que o Receptor possa } \\
\text { provar que estava } \\
\text { disponível antes de ser } \\
\text { fornecido pelo Grupo do } \\
\text { Fornecedor ou por seus } \\
\text { representantes, ou que foi } \\
\text { desenvolvido de forma } \\
\text { independente pelo } \\
\text { Receptor, sem violar } \\
\text { qualquer das suas } \\
\text { obrigações nos termos } \\
\text { deste Acordo; } \\
\text { (d) cujas divulgações } \\
\text { foram previamente } \\
\text { acordadas por escrito pelo } \\
\text { Fornecedor; ou } \\
\text { (e) que são obrigadas por } \\
\text { lei a serem divulgadas ou } \\
\text { por qualquer autoridade } \\
\text { regulamentar aplicável a } \\
\text { jurisdição a qual o } \\
\text { Receptor esteja sujeito. }\end{array}$ \\
\hline \multicolumn{3}{|c|}{ Sem Wordfast } \\
\hline $\begin{array}{l}\text { Aluno } 4 \\
\text { EXCEÇÃO E DIVULGAÇÃO } \\
\text { FORÇADA } \\
\text { As obrigações de } \\
\text { confidencialidade } \\
\text { contidas no presente }\end{array}$ & $\begin{array}{l}\text { Aluno } 5 \\
\text { EXCEÇÃO E DIVULGAÇÃO } \\
\text { FORÇADA } \\
\text { As obrigações de } \\
\text { confidencialidade } \\
\text { contidas nesse Contrato }\end{array}$ & $\begin{array}{l}\text { Aluno } 6 \\
\text { EXCEÇÃO E DIVULGAÇÃO } \\
\text { FORÇADA } \\
\text { As obrigações de } \\
\text { confidencialidade }\end{array}$ \\
\hline
\end{tabular}

TradTerm, São Paulo, v. 25, Agosto/2015, pp. 13-37 
Stupiello, E. N. De A.; Talhaferro, L. C. dos S. - As partes e o todo: possíveis efeitos dos sistemas de memórias de tradução na produção do tradutor em formação

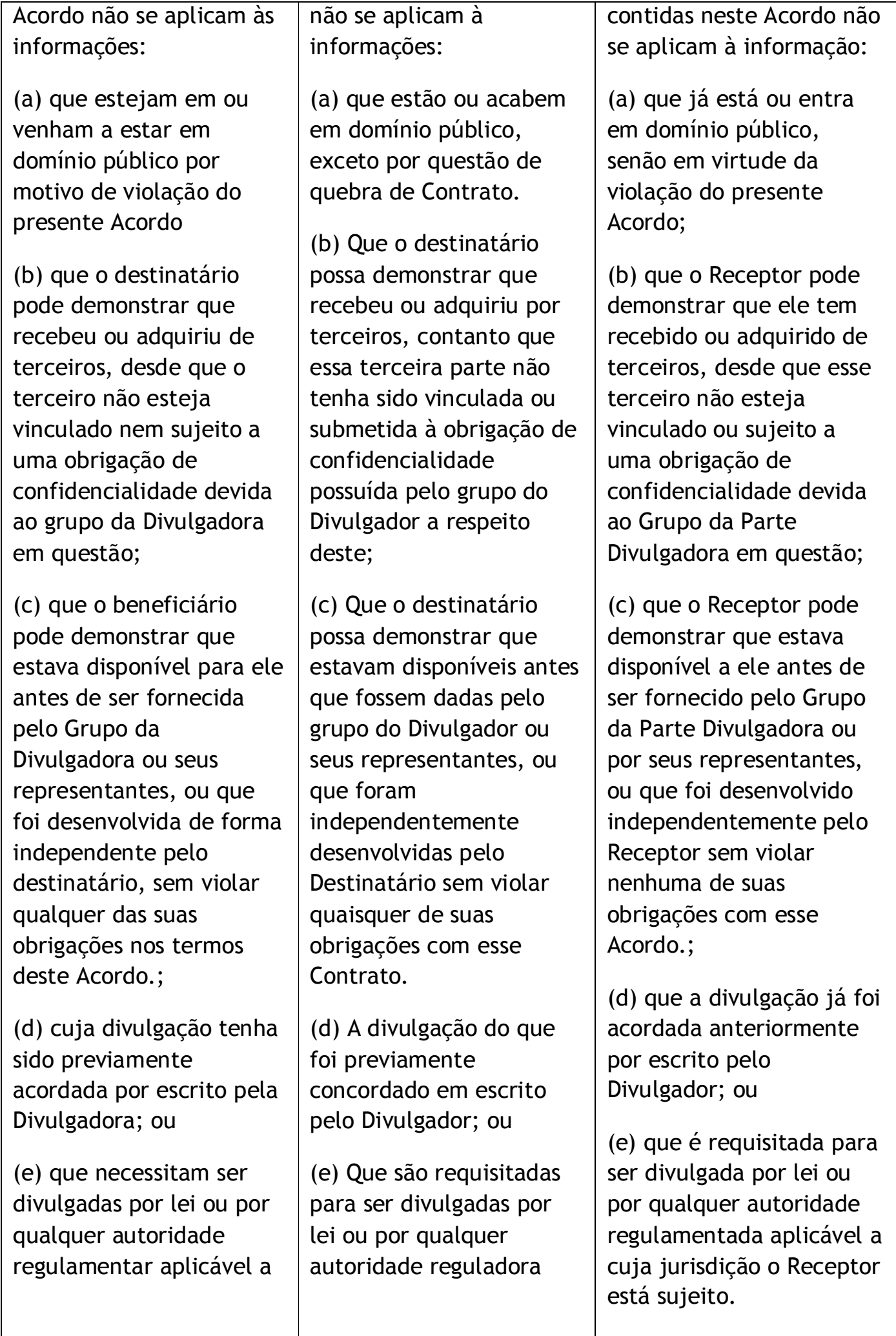

TradTerm, São Paulo, v. 25, Agosto/2015, pp. 13-37 
Stupiello, E. N. DE A.; TAlhaferro, L. C. dos S. - As partes e o todo: possíveis efeitos dos sistemas de memórias de tradução na produção do tradutor em formação

cuja jurisdição o

destinatário está sujeito. aplicável para a qual o

Destinatário é subjugado.

Neste trecho, pudemos notar discrepância na segmentação dos textos traduzidos com o Wordfast: a tradução produzida pelo Aluno 1 foi dividida em doze segmentos, um para o título da cláusula, um para a frase inicial da cláusula, um segmento para cada letra que abria os itens da cláusula - (a), (b), (c), (d) e (e) - e um para o conteúdo de cada item. Já a tradução realizada pelo Aluno 2 foi dividida entre sete segmentos: um para o título, um para a frase de abertura da cláusula e um para cada item dela, com as letras de listagem unidas aos seus respectivos itens.

A tradução do Aluno 3 possui onze segmentos. Ela estaria segmentada como a tradução do Aluno 1 caso não houvesse um problema na segmentação entre a frase de abertura da cláusula e a letra que lista o primeiro item. Como pode ser visto na imagem a seguir, ocorreu um erro na indicação dos tags (delimitadores) que dividem os segmentos. Tal erro pode ter sido causado pelo próprio Wordfast ou pelo usuário, que, ao editar o segmento, alterou os tags, causando o problema. De qualquer maneira, é possível perceber que o aluno não corrigiu a segmentação, apesar de o problema ser informado na caixa de diálogo do Wordfast. 
Stupiello, E. N. De A.; Talhaferro, L. C. dos S. - As partes e o todo: possíveis efeitos dos sistemas de memórias de tradução na produção do tradutor em formação

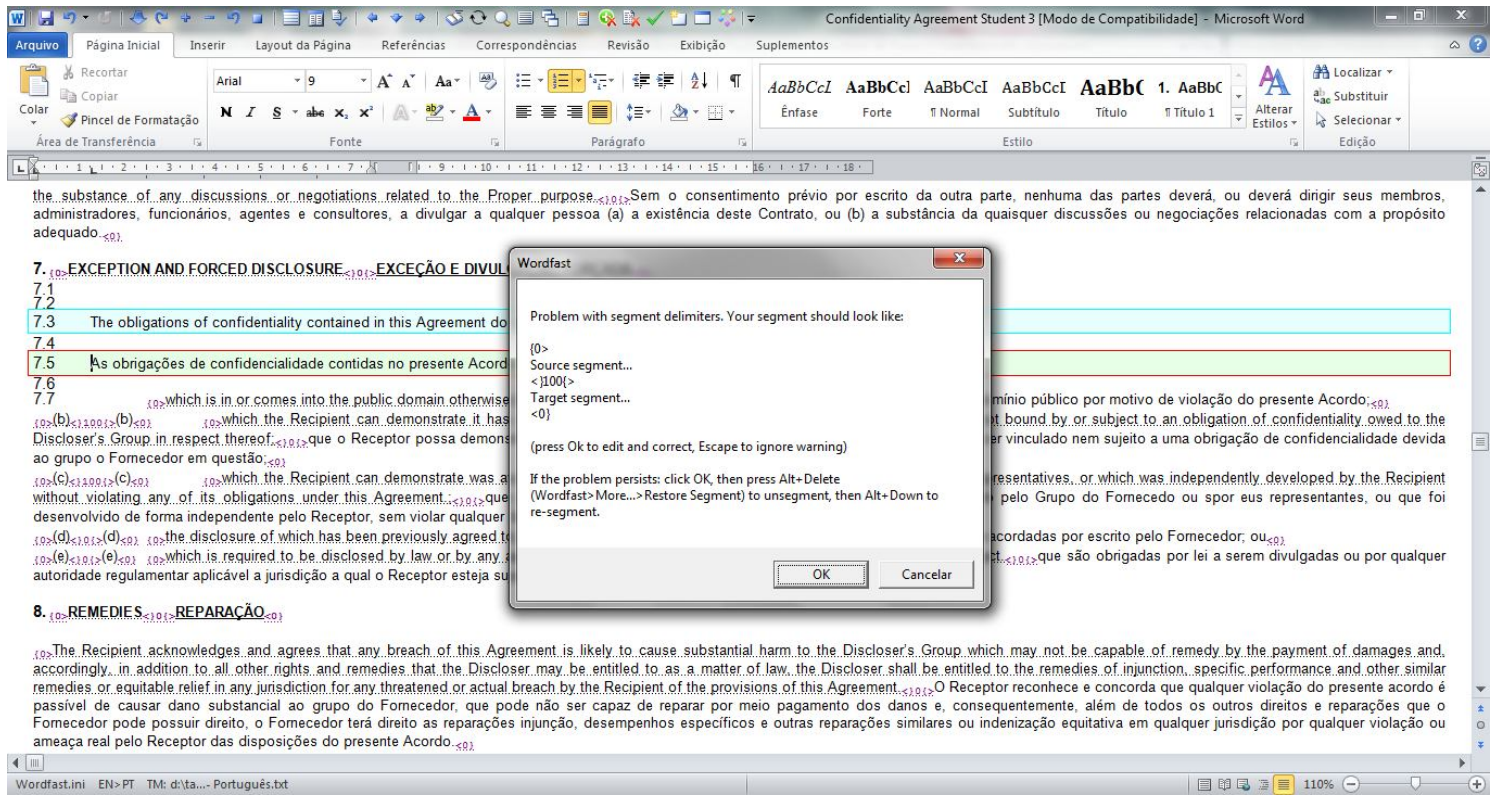

Figura 2: Problema na segmentação do Wordfast. É possivel perceber que houve um erro na indicação dos tags, delimitadores dos segmentos, que tanto pode ter sido causado pelo próprio Wordfast, quanto pelo usuário.

Atentamo-nos ao fato de que falta a tradução da frase de abertura da cláusula, "The obligations of confidentiality in this Agreement does not apply to information:", nos textos dos Alunos 2 e 3. Notamos que, quando abrimos o texto "sujo", isto é, contendo original e tradução divididos pelos marcadores, tanto o segmento original quanto sua tradução aparecem, mas, quando “limpamos” o texto, com auxílio da ferramenta Clean-up, essas unidades de tradução não ficam visíveis. Essa situação demonstra como um problema nos delimitadores do sistema pode influenciar na produção final da tradução, como ocorreu com o contrato analisado.

\subsection{Termo de condições para aluguel de veículos}

O termo de condições para o aluguel de veículos analisado neste trabalho é um documento emitido por uma agência norte-americana de aluguel de automóveis. O documento foi considerado relevante para análise porque, 
Stupiello, E. N. De A.; TAlhaferro, L. C. dos S. - As partes e o todo: possíveis efeitos dos sistemas de memórias de tradução na produção do tradutor em formação

apesar de ser considerado um texto com teor comercial, não apresenta a forma padrão de contrato, com identificação das partes, preâmbulo, cláusulas, mas é redigido de acordo com a norma culta da língua.

O trecho analisado trata das instruções sobre como sair do aeroporto da cidade de Miami e deslocar-se até a agência de aluguel de veículos.

\section{Trecho original 1: "SHUTTLE}

Upon arrival at the Miami International Airport, please follow signs to the Rental Car Center. Once you arrive at the Rental Car Center please proceed to the left and look for the sign OFF AIRPORT RENTAL CAR SHUTTLE. Proceed past that sign to the next sign that indicates SHUTTLES and follow that outside to pickup area 1 or 2. You will then board the Fox Rent A Car Shuttle for a two minute ride to the Fox Miami location."

\begin{tabular}{|c|c|c|}
\hline \multicolumn{3}{|c|}{ Com Wordfast } \\
\hline $\begin{array}{l}\text { Após a chegada, no } \\
\text { Aeroporto Internacional } \\
\text { de Miami, siga as placas } \\
\text { até o Centro de Aluguel } \\
\text { de Carros. Assim que } \\
\text { você chegar no Centro de } \\
\text { Aluguel de Carros, siga à } \\
\text { esquerda e procure pela } \\
\text { placa ÔNIBUS PARA } \\
\text { ALUGUEL DE CARROS } \\
\text { FORA DO AEROPORTO. } \\
\text { Siga em frente até a } \\
\text { próxima placa, que indica } \\
\text { ÔNIBUS e siga para a área } \\
\text { externa } 1 \text { ou } 2 \text {. Você } \\
\text { então pegará o ônibus da } \\
\text { Fox Rent A Car e em dois } \\
\text { minutos estará na filial de } \\
\text { Miami. }\end{array}$ & $\begin{array}{l}\text { Aluno } 2 \\
\text { TRANSPORTE } \\
\text { Chegando ao Aeroporto } \\
\text { Internacional de Miami, } \\
\text { por favor, siga as } \\
\text { indicações até o Rental } \\
\text { Car Center [Centro de } \\
\text { Locação de Automóvel]. } \\
\text { Ao chegar ao Centro } \\
\text { Locação de Automóvel, } \\
\text { siga para a esquerda e } \\
\text { procure pela placa OFF } \\
\text { AIRPORT RENTAL CAR } \\
\text { SHUTTLE. Siga este sinal e } \\
\text { vá até o próximo sinal } \\
\text { SHUTTLES; vá para fora } \\
\text { até os pontos de coleta } \\
\text { de passageiros } 1 \text { e } 2 \text {. Você } \\
\text { então embarcará no } \\
\text { transporte Fox Rent A } \\
\text { Car, para um percurso de }\end{array}$ & $\begin{array}{l}\text { Aluno } 3 \\
\text { LEVA E TRAZ } \\
\text { Depois de chegar no } \\
\text { Aeroporto Internacional } \\
\text { de Miami, por favor siga } \\
\text { as indicações para o } \\
\text { Centro de Aluguel de } \\
\text { Veículos. Uma vez que } \\
\text { você chegar no Centro de } \\
\text { Aluguel de Veículos, siga } \\
\text { para a esquerda e procure } \\
\text { a placa do leva e traz da } \\
\text { locadora de veículos } \\
\text { saindo do aeroporto. } \\
\text { Prossiga depois da placa } \\
\text { até a próxima escrita } \\
\text { LEVA E TRAZ e siga até a } \\
\text { área externa de } \\
\text { transporte } 1 \text { ou } 2 \text {. } \\
\text { Embarque no Leva e Traz } \\
\text { da Fox Rent A Car para } \\
\text { uma viagem de dois }\end{array}$ \\
\hline
\end{tabular}

TradTerm, São Paulo, v. 25, Agosto/2015, pp. 13-37

www.usp.br/tradterm

http://www.revistas.usp.br/tradterm/index 
Stupiello, E. N. De A.; Talhaferro, L. C. dos S. - As partes e o todo: possíveis efeitos dos sistemas de memórias de tradução na produção do tradutor em formação

\begin{tabular}{|c|c|c|}
\hline & $\begin{array}{l}\text { dois minutos até nossa } \\
\text { locadora Fox Miami. }\end{array}$ & $\begin{array}{l}\text { minutos até a locadora } \\
\text { Fox Miami. }\end{array}$ \\
\hline \multicolumn{3}{|c|}{ Sem Wordfast } \\
\hline $\begin{array}{l}\text { Aluno } 4 \\
\text { TRANSPORTE Chegando } \\
\text { ao Aeroporto } \\
\text { Internacional de Miami, } \\
\text { por favor, siga as } \\
\text { indicações até o Rental } \\
\text { Car Center [Centro de } \\
\text { Locação de Automóvel]. } \\
\text { Ao chegar ao Centro } \\
\text { Locação de Automóvel, } \\
\text { siga para a esquerda e } \\
\text { procure pela placa OFF } \\
\text { AIRPORT RENTAL CAR } \\
\text { SHUTTLE. Siga este sinal } \\
\text { e vá até o próximo sinal } \\
\text { SHUTTLES; vá para fora } \\
\text { até os pontos de coleta } \\
\text { de passageiros } 1 \text { e } 2 . \\
\text { Você então embarcará no } \\
\text { transporte Fox Rent A } \\
\text { Car, para um percurso de } \\
\text { dois minutos até nossa } \\
\text { locadora Fox Miami. }\end{array}$ & $\begin{array}{l}\text { Aluno } 5 \\
\text { TRANSPORE [sic] Na } \\
\text { chegada ao Aeroporto } \\
\text { Internacional de Miami, } \\
\text { por favor siga os sinais } \\
\text { até o Rental Car Center. } \\
\text { Quando você chegar no } \\
\text { Rental Car Center por } \\
\text { favor vire a esquerda e } \\
\text { olhe para a placa OFF } \\
\text { AIRPORT RENTAL CAR } \\
\text { SHUTTLE (TRANSPORTE } \\
\text { PARA ALUGUEL DE CARRO } \\
\text { FORA DO AEROPORTO). } \\
\text { Passe pela placa até a } \\
\text { próxima que indica } \\
\text { SHUTTLES (TRANSPORTES) } \\
\text { e vá para fora do } \\
\text { aeroporto para pegá-lo na } \\
\text { área de traslado } 1 \text { ou } 2 . \\
\text { Você entrará na van da } \\
\text { FOX rent a car para um } \\
\text { trajeto de } 2 \text { minutos até a } \\
\text { FOX Miami. }\end{array}$ & $\begin{array}{l}\text { Aluno } 6 \\
\text { TRANSPORTE } \\
\text { Ao chegar ao Aeroporto } \\
\text { Internacional de Miami, } \\
\text { por favor, siga as placas } \\
\text { ao Rental Car Center } \\
\text { [Centro de Aluguel de } \\
\text { Carros]. Ao chegar ao } \\
\text { Centro de Aluguel de } \\
\text { Carros siga para a } \\
\text { esquerda e procure pela } \\
\text { placa OFF AIRPORT } \\
\text { RENTAL CAR SHUTTLE } \\
\text { Continue depois dessa } \\
\text { placa até outra que } \\
\text { indique SHUTTLES; siga vá } \\
\text { para fora até os pontos de } \\
\text { coleta de passageiros } 1 \text { e } \\
\text { 2. Então você embarcará } \\
\text { para um percurso de dois } \\
\text { minutos na Fox Rent A Car } \\
\text { Shuttle até a locadora Fox } \\
\text { Miami. }\end{array}$ \\
\hline
\end{tabular}

Neste trecho, observamos problemas relacionados à segmentação nos textos em que o sistema foi utilizado. O trecho analisado deveria ter cinco segmentos, divididos pelos pontos finais que os delimitam; porém, conta com apenas quatro segmentos. Isso porque o sistema de memória não dividiu dois períodos, que resultaram em um único segmento. Os alunos optaram por não editar o segmento manualmente e traduziram os dois períodos em um único segmento.

TradTerm, São Paulo, v. 25, Agosto/2015, pp. 13-37

www.usp.br/tradterm

http://www.revistas.usp.br/tradterm/index 
Stupiello, E. N. De A.; TAlhaferro, L. C. Dos S. - As partes e o todo: possíveis efeitos dos sistemas de memórias de tradução na produção do tradutor em formação

Uma possível influência da língua inglesa no texto dos alunos 2, 4 e 5 é a tradução de "sign" por "sinal". No contexto do trecho analisado, a tradução mais adequada seria "placa". Essa inadequação poderia ser evitada com um processo de revisão mais cuidadoso, assim como o erro de digitação da palavra "transporte", que foi escrita "transpore" pelo Aluno 5. Esse erro, armazenado na memória, pode ser facilmente propagado e ser recuperado em outros trabalhos. A revisão também seria importante para evitar erros de regência verbal, como o cometido pelos alunos 1 e 3, que utilizaram "em" como preposição no lugar de "a" como complemento de "chegar": "Assim que você chegar no Centro de Aluguel de Carros" e "Depois de chegar no Aeroporto Internacional de Miami".

Apesar de a análise contrastiva ter nos permitido concluir que o uso do sistema de memórias de tradução não influenciou de forma significativa na interpretação dos estudantes participantes do estudo, observamos que houve efeito na organização dos textos analisados, especialmente na divisão dos períodos, o que resultou em diferenças nas traduções finais realizadas com e sem o auxílio dessa ferramenta.

\section{Considerações finais}

Apesar de conduzido com um pequeno grupo de tradutores em formação, este estudo apresentou alguns exemplos de como a segmentação textual executada pelo sistema de memória pode influenciar na produção final de uma tradução. Embora não tenham sido encontradas diferenças estatisticamente relevantes entre trabalhos realizados com e sem o auxílio do sistema de memória, observou-se que o índice de semelhança entre os trabalhos finais, as traduções, foi maior nas situações em que foi utilizado um sistema de memória durante o desenvolvimento do trabalho. 
Stupiello, E. N. DE A.; TAlhaferro, L. C. dos S. - As partes e o todo: possíveis efeitos dos sistemas de memórias de tradução na produção do tradutor em formação

Diferentemente da prática de trabalho comum em agências de tradução, conforme reportadas por LeBlanc (2013), por exemplo, os estudantes participantes da pesquisa não receberam instruções específicas sobre como o sistema deveria ser utilizado e nem foram forçados ou encorajados a utilizar as opções armazenadas na memória de tradução quando apropriado. Os resultados talvez fossem diferentes se tivéssemos aderido à prática adotada pelas agências.

Observou-se, pelas produções analisadas, que o tradutor que emprega um sistema de memória muda seu foco de atenção do texto como um todo para o segmento que the é apresentado para tradução. Em vista dessa questão, considera-se relevante a realização de um estudo mais amplo, envolvendo outros tipos de textos traduzidos com e sem o auxílio de sistemas de memórias.

Uma ocorrência observada nas traduções apontou para um possível problema quando se utiliza um sistema de memória. Um erro de digitação, como apresentado, pode ser facilmente propagado, uma vez que o sistema não detecta falhas, mas apresenta um segmento como correspondente. Bowker (2002) e LeBlanc (2013) reportam que, se uma memória não passa por constante manutenção, problemas como mais de uma opção de tradução para um mesmo termo ou opções de tradução inadequadas podem tornar-se comuns e, caso o tradutor que utilize essa memória sem refletir criticamente sobre ela, esses erros podem ser multiplicados em larga escala. Como possível solução para esse problema, LeBlanc (2013) indica o treinamento do tradutor em formação nesse tipo de ferramenta, para que possa utilizá-la conscientemente, aproveitando seus benefícios e corrigindo seus erros.

Além da manutenção constante da memória, Bowker (2005) sugere que o texto traduzido seja revisto como um todo, para que sejam realizadas modificações relativas à coesão e à coerência. Porém, com a utilização cada vez mais frequente de sistemas de memórias de tradução "na nuvem”, ou seja, online, muitas vezes o tradutor não tem acesso à sua produção final, pelo fato de tanto o texto original, quanto sua tradução e, ainda, o banco de dados não 
Stupiello, E. N. De A.; TAlhaferro, L. C. Dos S. - As partes e o todo: possíveis efeitos dos sistemas de memórias de tradução na produção do tradutor em formação

possam ser baixados pelos próprios profissionais que realizaram o serviço de tradução.

Além de sistemas online, cada vez mais os sistemas de memórias de tradução oferecem programas de tradução automática entre os seus recursos. Se, em um passado não tão distante, o uso da tradução automática aliado às memórias de tradução era combatido pelos profissionais e estudiosos da área, como aconselhado por Biau Gil \& Pym (2006: 17), "se [um cliente] disser que um texto já foi traduzido por uma máquina e você só tem que corrigir os erros, procure outro cliente", a combinação atual com os sistemas de memórias é uma realidade que visa a atender à demanda cada vez maior de textos em prazos cada vez menores quanto pelo desejo dos clientes de pagar cada vez menos pelos serviços de tradução.

A (semi)automação do trabalho de tradução, uma realidade cada vez mais constante em nossa era, tem efeitos em questões que abrangem desde a formação acadêmica do tradutor até o papel desse profissional no mercado de trabalho. Se, em meados do século XX, o tradutor sentia que sua profissão era ameaçada pela máquina, atualmente, com a crescente automação de seu trabalho, ele pode acabar se tornando um revisor da produção de um programa automático. Em vez de a máquina recuperar o resultado do trabalho do tradutor, seria ele quem lidaria com a produção da máquina. Essa constatação, relatada a partir da mudança observada nos sistemas de memórias, que já incorporaram programas de tradução automática entre seus recursos, fomenta um encaminhamento futuro da pesquisa em tradução. A análise de como a tradução previamente realizada pela máquina, associada ao uso dos sistemas de memórias de tradução na etapa da pós-edição pode produzir reflexões importantes sobre quais podem ser os novos rumos da profissão e como estar mais bem preparado para eles. 
Stupiello, E. N. DE A.; TAlhaferro, L. C. dos S. - As partes e o todo: possíveis efeitos dos sistemas de memórias de tradução na produção do tradutor em formação

\section{Referências bibliográficas}

AUSTERMÜHL, F. Electronic tools for translators. Manchester: St. Jerome, 2001.

BIAU GIL, J. R.; PYM, A. Technology and translation (a pedagogical overview). In: Pym, A.; Perekrestenko, A.; Starink, B. Translation technology and its teaching. Tarragona, Espanha, 2006. Disponível em: www.isg.urv.es/publicity/isg/publications/technology_2006. Acesso em: 22 fev. 2015.

BOWKER, L. Productivity vs. quality? A pilot study on the impact of translation memory systems. Localization Focus, Dublin, v. 4, n. 1, 2005, pp. 13-20. Disponível em: www.localisation.ie/oldwebsite/resources/lfresearch/Vol4_1Bowker.pdf. Acesso em: 23 maio 2014. . Computer-aided translation: a practical introduction. Ottawa: Ottawa University Press, 2002.

BRASIL. Ministério da Saúde. SISNEP: Sistema Nacional de Informações sobre Ética em Pesquisa envolvendo Seres Humanos. Introdução. DATASUS. [Brasília, 2012]. Disponível em: www.portal2.saude.gov.br/sisnep/Menu_Principal.cfm. Acesso em: 15 maio 2014.

CRONIN, M. Translation and the global economy. In: - Translation and globalization. London: Routledge, 2003: 8-41.

ESSELINK, B. A practical guide to localization. Amsterdam: John Benjamins, 2000.

FOX RENT A CAR. Rental policies. [s. n.], c2014. Disponível em: www.foxrentacar.com/rental-policies/lax.aspx. Acesso em: 9 out. 2014.

LEBLANC, M. Translators on translation memory (TM). Results of an ethnographic study in three translation services and agencies. Translation \& Interpreting, Sidney, v. 5, n. 2, 2013, pp. 01-13. Disponível em: www.transint.org/index.php/transint/article/view/228/134. Acesso em: 23 maio 2014.

SOMERS, H. Translation Memory Systems. In: SOMERS, H. (ed.), Computers and Translation: A Translator's Guide. Amsterdam/Philadelphia: John Benjamins, 2003: 31-46.

TURNITIN: uma solução completa para avaliar o trabalho escrito. Página inicial. Newcastle upon Tyne, [2014]. Disponível em: www.turnitin.com. Acesso em: 16 mar. 2014.

WEININGER, M. J. TM E MT na tradução técnica globalizada: tendências e consequiências. In: RochA, M. et al. (Org.). Cadernos de Tradução, Florianópolis, n. 14, 2004, pp. 243-263.

TradTerm, São Paulo, v. 25, Agosto/2015, pp. 13-37

www.usp.br/tradterm

http://www.revistas.usp.br/tradterm/index 
Stupiello, E. N. De A.; TAlhaferro, L. C. Dos S. - As partes e o todo: possíveis efeitos dos sistemas de memórias de tradução na produção do tradutor em formação

WORDFAST CLASSIC. Version 6.13. Disponível em: www.wordfast.net. Acesso em: 10 jan. 2015.

Recebido em: 10 mar. 2015

Aprovado em: 13 maio 2015

TradTerm, São Paulo, v. 25, Agosto/2015, pp. 13-37

www.usp.br/tradterm

http://www.revistas.usp.br/tradterm/index 